\title{
PHYTOCHEMICAL SCREENING OF DIFFERENT ROOT EXTRACTS OF Ageratum conyzoides AND THEIR POTENTIAL BIOACTIVE PROPERTIES
}

\section{Tanveer Ahmad ${ }^{1}$, Tahir Rasheed ${ }^{2 *}$, Sarmad Ahmad Qamar ${ }^{3}$, Muhammad Bilal $^{4 *}$}

\author{
${ }^{1}$ School of Chemistry and Chemical Engineering, Shanghai Jiao Tong University, Shanghai 200240, China \\ ${ }^{2}$ Interdisciplinary Research Center for Advanced Materials, King Fahd University of Petroleum and Minerals (KFUPM), Dhahran 31261, Saudi Arabia. \\ ${ }^{3}$ State Key Laboratory of Bioreactor Engineering and School of Biotechnology, East China University of Science and Technology, Shanghai, 200237, China. \\ ${ }^{4}$ School of Life Science and Food Engineering, Huaiyin Institute of Technology, Huaian, 223003, China.
}

Received - July 02, 2021; Revision - September 08, 2021; Accepted - September 21, 2021

Available Online - October 30, 2021

DOI: http://dx.doi.org/10.18006/2021.9(5).639.646

KEYWORDS
Phytochemical screening
Antimicrobial activity
Antioxidant activity
Traditional medicines
Medicinal plants

\begin{abstract}
The present study was conducted to determine different classes of secondary metabolites of Ageratum conyzoides root extracts and to evaluate their antioxidant, antibacterial, and antifungal potentialities using various pathogenic fungal and different gram-positive/gram-negative bacterial strains. The roots powder was subjected to ultrasonic-assisted extraction with $n$-hexane, acetone, ethanol, and EtOH: $\mathrm{H}_{2} \mathrm{O}(1: 1)$. The screening of phytochemicals indicated the existence of terpenoids, alkaloids, coumarins, sterols, flavonoids, and glycosides in the root extract of A. conyzoides. However, the absence of saponins, tannins, anthocyanidins, anthraquinones, and phlobatannins was observed. The results indicated a reasonable antibacterial (against gram-negative and gram-positive bacteria), and antifungal potential. The antibacterial activity of the ethanolic extract was highest against all four strains of bacteria and was also comparable to the standard medicines used. However, antifungal activity was highest in EtOH: $\mathrm{H}_{2} \mathrm{O}$ (1:1) extract. Moderate antioxidant properties were also demonstrated, favoring the importance of the roots of this plant from a medicinal point of view.
\end{abstract}

* Corresponding author

E-mail: masil@sjtu.edu.cn, tahir.rasheed@hotmail.com (T. Rasheed); bilaluaf@hotmail.com (M. Bilal)

Peer review under responsibility of Journal of Experimental Biology and Agricultural Sciences.

Production and Hosting by Horizon Publisher India [HPI] (http://www.horizonpublisherindia.in/).

All rights reserved.
All the articles published by Journal of Experimental Biology and Agricultural Sciences are licensed under a Creative Commons Attribution-NonCommercial 4.0 International License Based on a work at www.jebas.org.

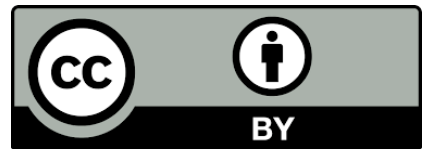




\section{Introduction}

Ageratum conyzoides is a weed commonly present in cultivated lands,e.g., wastelands, grasslands, pastures, and even in forests areas (Batish et al., 2006; Harjanti et al., 2019). This plant is commonly found in subtropical and tropical regions of the world. It has spread to Southeast Asia, West Africa, South America, Southeastern North America, Central America, the Caribbean, and Florida (USA) (Okunade 2002; Bamidele et al., 2010). In Pakistan, it is widely distributed in Islamabad, Rawalpindi, and Changa Manga Forest near Lahore (Zafar et al., 2006). The roots and leaves of A.conyzoides are of great medicinal value. They are used for the treatment of an array of disorders such as burns and wounds. Due to excellent antioxidant, antibacterial, and antifungal properties, medicinal plants have been used for several bacterial infections, dyspnea, arthrosis, headaches, analgesic, antiinflammatory, pneumonia, anti-asthmatic, anti-spasmodic, and haemostatic effects, stomach ailments, gynaecological diseases, and other skin disorders (Sachin et al., 2009; Kamboj et al., 2010; Al-Kaabi et al., 2021). In a murine ascites Dalton's lymphoma invivo, the aqueous extract of roots of $A$. conyzoides declined glutathione in the liver and the lymphoma cells of the tumorbearing mice. In the opinion of the authors, this could be one step in producing the anti-tumor effect (Rosangkima \& Prasad, 2004).

There is a growing scientific concern in finding plants having high medicinal potential. Due to their chemical structure, plant extracts have been shown to exhibit improved capability to substitute these mediators of their multi-step processes for the efficient treatment of painful and inflammatory processes (Wang et al., 2013; Khalid et al., 2017a,b,c; Bilal et al., 2018; Shafiq et al., 2021). Nowadays, diarrhea is a very common disease in several countries, and it is the leading cause of morbidity and mortality, especially among the lower-age population (Wendel et al., 2008; Muhammad et al., 2012). Medicinal plants have a central role in the advancements of modern technologies on anti-diarrheal activities of naturally extracted compounds (Panda et al., 2012; Rawat et al., 2017). S. aureus, also known as golden staph causes pimples, scalded skin, pneumonia, and toxic shock syndrome. Pseudomonas aeruginosa is a casual microorganism of the urinary tract, pulmonary tract, and blood infections, while Klebsiella pneumonia causes pneumonia, wound infection, diarrhea, urinary tract infections, and upper respiratory tract infection. The research for efficient and safer agents for biomedical purposes has continued to be a hot area among the scientific community (Ishaq et al., 2019; Khalid et al., 2019; Bilal et al., 2020; Munir et al., 2021). Therefore, the WHO has encouraged scientific work on the evaluation of traditional medicinal plants for the treatment of common health-causing issues worldwide (Uddin et al., 2009; Al-Kaabi et al., 2021). This study was designed to determine the phytochemicals present in the root extract of A.conyzoides. Moreover, the evaluation of their antioxidant, antibacterial and antifungal potential was a key purpose of broadening the role of A. conyzoides chemicals in the modern biomedical industry.

\section{Materials and Methods}

\subsection{Collection of raw materials}

The root samples of A.conyzoides were obtained from I-9/4 Islamabad, Punjab-Pakistan. The plant species (specimen number84902) was authenticated by the Department of Plant Sciences, Quaid-i-Azam University, Islamabad, Pakistan. The samples were preserved in the herbarium of the Department of Plant Sciences. The plant specimen was cleaned with tap water and air-dried before preservation.

\subsection{Development of plant extract}

Powdered $(1.5 \mathrm{~kg})$ roots were successively extracted with the increased polarity of solvents such as $n$-hexane, dimethyl ketone $\left(\mathrm{Me}_{2} \mathrm{CO}\right)$, ethanol (EtOH), and EtOH: $\mathrm{H}_{2} \mathrm{O}$ (1:1). At each stage, a sufficient amount of solvent was added, and the resulting slurry was subjected to mechanical stirring for at least $24 \mathrm{~h}$. The slurry was also irradiated with ultrasonic waves for efficient extraction. The extract was decanted, and the solvent was driven off under the vacuum. Plant extracts with $1 \mathrm{mg} / \mathrm{ml}$ concentration were used for the determination of bioactivities.

\subsection{Screening of phytochemicals}

The phytochemicals screening of the above-mentioned plant extracts was performed by following the previously reported protocols of Trease \& Evans (1989) and Cannell, (1998). A brief description of methodologies has been given in sub-sections below to determine the secondary metabolites such as alkaloids, tannins, saponins, flavonoids, terpenoids, sterols, glycosides, coumarins, anthraquinones, anthocyanidins, and phlobatannins (Okamoto et al., 2006; Tiwari et al., 2011; Ganesh et al., 2011; Mulugeta et al., 2021)

\subsubsection{Alkaloids (Dragendroff's test)}

For the determination of alkaloids, plant extracts $(0.2 \mathrm{~g})$ were added with $2 \%$ sulfuric acid and incubated for 2 minutes. The mixtures were filtered using filter paper, and a few drops of Dragendroff's reagent were added. The formation of orange-red precipitates indicated the existence of alkaloids in root extracts.

\subsubsection{Tannins $\left(\mathrm{FeCl}_{3}\right.$ test $)$}

The plant extracts $(0.5 \mathrm{~g})$ were added to a test tube containing 10 $\mathrm{mL}$ of $\mathrm{H}_{2} \mathrm{O}$. The samples were boiled and filtered. Few drops of $\mathrm{FeCl}_{3}(0.1 \%)$ were added. The appearance of blue-black or brownish-green coloration confirmed the existence of tannins in the root extracts of the plant. 


\subsubsection{Saponins (Frothing test)}

The plant extracts $(0.5 \mathrm{~g})$ were dissolved in boiling water. The mixtures were gently shaken for mixing and allowed to cool for a few minutes. Persistent froth appeared indicating the existence of saponins in the extracts.

\subsubsection{Flavonoids (Alkali test)}

The plant extracts $(0.2 \mathrm{~g})$ were dispersed in dilute sodium hydroxide and added with the dilute $\mathrm{HCl}$. The yellowish color of the solution was disappeared indicating the existence of flavonoids in the plant extracts.

\subsubsection{Terpenoids (Salkowski test)}

The roots extracts $(0.5 \mathrm{~g})$ were added with $\mathrm{CHCl}_{3}(2 \mathrm{~mL})$ along with concentrate $\mathrm{H}_{2} \mathrm{SO}_{4}(3 \mathrm{~mL})$. The appearance of the reddish-brown color of the interface indicated the existence of terpenoids in plant extracts.

\subsubsection{Sterols (Lieberman-Burchard reaction)}

The concentrate $\mathrm{H}_{2} \mathrm{SO}_{4}(1 \mathrm{~mL})$ was added to $1 \mathrm{~mL}$ of each extract of $A$. conyzoides roots using a test tube. The appearance of a red coloration indicated the existence of sterols in plant extracts.

\subsubsection{Glycosides (Keller-Killiani test)}

The root extracts $(0.5 \mathrm{~g})$ were diluted by the addition of $\mathrm{H}_{2} \mathrm{O}$ (5 $\mathrm{mL})$, followed by the addition of glacial HOAc $(2 \mathrm{~mL})$. The mixture was added with one drop of $\mathrm{FeCl}_{3}$ solution and $1 \mathrm{~mL}$ of concentrate $\mathrm{H}_{2} \mathrm{SO}_{4}$. The interfacial brown ring formation showed the existence of deoxy-sugar properties of glycosides.

\subsubsection{Coumarins ( $\mathrm{NaOH}$ test)}

The root extracts $(0.5 \mathrm{~g})$ were taken in test tubes, wrapped with filter paper, and soaked with $\mathrm{NaOH}(1 \mathrm{M})$. Test tubes were kept in a water bath for few minutes. The test tubes were examined under UV light for yellow fluorescence which showed the existence of coumarins.

\subsubsection{Anthraquinones}

Plant extracts $(0.5 \mathrm{~g})$ were placed in $10 \%$ of $\mathrm{HCl}$ and boiled for few minutes in the water bath. After gentle filtration, the mixtures were allowed to cool. The mixture was equilibrated with $\mathrm{CHCl}_{3}$ along with a few drops of $10 \%$ solution of $\mathrm{NH}_{3}$. The mixture was heated, and the formation of rose-pink color confirmed the presence of anthraquinones.

\subsubsection{Anthocyanidins}

The root extracts $(0.5 \mathrm{~g})$ were added with $\mathrm{HCl}(1 \mathrm{~mL})$. The presence of red coloration indicated the existence of anthocyanidins.

\subsubsection{Phlobatannins}

The root extracts $(0.5 \mathrm{~g})$ were mixed in $\mathrm{dH}_{2} \mathrm{O}$ and filtered. The filtered solution was boiled with $2 \%$ of $\mathrm{HCl}$. The formation of red precipitates confirmed the existence of phlobatannins.

\subsection{Determination of antibacterial activity}

Antibacterial activities of different root extracts were analyzed against four different bacteria (Bacillus subtilis-ATCC 6059, Streptococcus aureus-ATCC 6538, Klebsiella pneumonia-ATCC 4352, and Pseudomonas aeruginosa-ATCC 7221) using the previously described protocol (Mehreen et al., 2016). For this purpose, samples were prepared by mixing crude extracts $(1 \mathrm{mg})$ in $1 \mathrm{~mL}$ of dimethyl sulfoxide (DMSO) as a negative control, whereas two different antibiotics were used as a positive control e.g., Chloramphenicol (positive control-1) and Streptomycetes (positive control-2). The nutrient agar media was prepared by the standard protocol. Seeded agar plates were prepared by pouring 75 $\mathrm{mL}$ of media into the petri dish. When the agar was solidified, the sterile cork borer $(5 \mathrm{~mm})$ was used for the formation of four wells per plate. The samples $(100 \mu \mathrm{L})$ were poured along with the positive as well as a negative control in the respective wells of the petri dish with the help of a micropipette. The plates were placed at $37{ }^{\circ} \mathrm{C}$ for incubation. After $24 \mathrm{hrs}$, the zone of inhibition was calculated with the help of a scale.

\subsection{Determination of antifungal activity}

Antifungal activities of crude root extracts were analyzed using the agar-tube-dilution process (Washington \& Sutter, 1980). Two toxic fungal strains (Fusarium moniliforme and Helminthosporium sativum) were used for the evaluation of antifungal potentialities. The strains were obtained from the Microbiology Department of Quaid-i-Azam University, Pakistan. Both fungal cultures were maintained on Sabouraud dextrose agar (SDA) media at kept at refrigerator temperature $\left(4{ }^{\circ} \mathrm{C}\right)$. The samples were prepared from the initial stock of $1 \mathrm{mg}$ of crude extracts in $1 \mathrm{~mL}$ of DMSO. Another tube from each specimen was prepared without plant extract which acted as a negative control. While standard fungicide Chloramphenicol $(1 \mathrm{mg} / \mathrm{ml})$ was kept as a positive control. The test tubes were placed at 28 ${ }^{\circ} \mathrm{C}$ for seven days. Inhibition of fungal growth was measured by the length of fungal growth, and the growth inhibition was analyzed according to positive and negative controls. Percent inhibition of fungal growth for each sample was determined by the following formula:

$$
\begin{aligned}
& \text { Percent inhibition of fungal growth } \\
& =\frac{100-\text { Linear growth in sample test tube }(\mathrm{mm})}{\text { Linear growth in control test tube }(\mathrm{mm})} \times 100
\end{aligned}
$$




\subsection{Determination of antioxidant activity}

For the determination of antioxidant potentialities, different concentrations of the test sample and standard (ascorbic acids) were prepared e.g., 100, 50, 25, 12.5, 6.25, 3.15, and $1.56 \mu \mathrm{g} / \mathrm{mL}$, respectively. A set of three clean and dry test tubes were taken and $2.7 \mathrm{~mL}$ of DPPH solution was added to each test tube. Ascorbic acid solution $(0.3 \mathrm{~mL})$ in EtOH was added in another three test tubes including $2.7 \mathrm{~mL}$ of DPPH solution. Twenty-one clean and dry test tubes were taken in which $2.7 \mathrm{~mL}$ of DPPH reagent and $0.3 \mathrm{~mL}$ of different concentrations of test sample $(100,50,25$, $12.5,6.25,3.15$, and $1.56 \mu \mathrm{g} / \mathrm{mL}$ ) concentrations were added and mixed thoroughly. Seven test tubes were taken in which $0.3 \mathrm{~mL}$ of various concentrations of test samples $(100,50,25,12.5,6.25$, 3.15 , and $1.56 \mu \mathrm{g} / \mathrm{mL}$ ) and $2.7 \mathrm{~mL}$ EtOH solvent were added and run in UV as blank. After $30 \mathrm{~min}$ incubation period at $37{ }^{\circ} \mathrm{C}$ in dark, the absorbance of the standard solution and the resulting mixtures was determined at $517 \mathrm{~nm}$ with UV/vis spectrophotometer (model UV-1700 (E) 23 OCE, Schimadzu, Japan).

\section{Results and Discussion}

\subsection{Screening of phytochemicals}

Phytochemical screening of four different extracts i.e., $n$-hexane, acetone, ethanol, and EtOH: $\mathrm{H}_{2} \mathrm{O}$ (1:1) of A. conyzoides was carried out to determine the detailed information regarding phytochemical constituents of A. conyzoides roots, which may provide an incentive for proper evaluation of this plant for its medicinal potential. Table 1 summarizes the results obtained after the screening of secondary metabolites whose presence was indicated by the above-mentioned phytochemical tests. According to the results obtained phlobatannins, anthraquinones, anthocyanidins, saponins, and tannins were absent in all extracts. However, flavonoids, glycosides, sterols, terpenoids, and alkaloids were found in all plant extracts except for flavonoids which were absent in $n$-hexane extract and cardiac glycosides in EtOH: $\mathrm{H}_{2} \mathrm{O}(1: 1)$ extract. Coumarins were also absent in $n$-hexane and EtOH: $\mathrm{H}_{2} \mathrm{O}$ (1:1) extracts but present in acetone and ethanol extracts. Therefore, it is concluded that phytoconstituents isolated from $A$. conyzoides roots possess a wide range of biological activities. However, their effects on the cardiovascular system, diuresis, antiviral, spasmolytic, anti-inflammatory, and other biomedical properties are yet to be studied. Phytochemical constituents and their biological activities showed the medicinal importance of this plant (Kamboj et al., 2011; Al-Kaabi et al., 2021). Parveen et al., (2014) studied the efficiency of Artemisia absinthium and A. conyzoides in-vitro on Rhipicephalus microplus using the AIT test. Five different concentrations of plant extract from $1.25-20 \%$ were used in the evaluation process. The results revealed $66.7 \%$ and $40 \%$ of mortality at $20 \%$ concentration of A.absinthium and A.conyzoides, respectively. A.conyzoidesreduced $90 \%$ of egg hatching; however, A. absinthium indicated $100 \%$ inhibition. The study revealed that A.absinthium presents higher acaricidal characteristics. Chah et al., (2006) reported excellent antibacterial and wound healing properties of A. absinthium.

\subsection{Antibacterial activities}

Antibacterial activity of different root extracts was determined against four different bacteria [Gram-positive e.g., $B$. subtilis(ATCC 6059), S. aureus(ATCC 6538), and Gram-negative e.g., K. pneumonia(ATCC 4352) and P. aeruginosa (ATCC 7221)] using agar-well-diffusion method. Bioassays of four different extracts of roots of A.conyzoides was carried out to compare the relative activities of these extracts. In the current study, the results

Table 1 Screening of phytochemicals of the different root extracts of A. conyzoides.

\begin{tabular}{|c|c|c|c|c|c|}
\hline \multirow{2}{*}{ S. No. } & \multirow{2}{*}{ Metabolites } & \multicolumn{4}{|c|}{ Extracts } \\
\hline & & $n$-hexane & $\mathrm{Me}_{2} \mathrm{CO}$ & $\mathrm{EtOH}$ & $\mathrm{EtOH}: \mathrm{H}_{2} \mathrm{O}(1: 1)$ \\
\hline 1 & Alkaloids & + & + & + & + \\
\hline 2 & Tannins & - & - & - & - \\
\hline 3 & Saponins & - & - & - & - \\
\hline 4 & Sterols & + & + & + & + \\
\hline 5 & Flavonoids & - & + & + & + \\
\hline 6 & Terpenoids & + & + & + & + \\
\hline 7 & Glycosides & + & + & + & - \\
\hline 8 & Coumarins & - & + & + & - \\
\hline 9 & Anthocyanidins & - & - & - & - \\
\hline 10 & Anthraquinones & - & - & - & - \\
\hline 11 & Phlobatannins & - & - & - & - \\
\hline
\end{tabular}

Journal of Experimental Biology and Agricultural Sciences http://www.jebas.org 
signified that all the crude extracts have exhibited strong in-vitro antibacterial activities against the different bacteria that was employed in the experiments in various degrees. The bioassays findings have been represented in Figure 1. These results showed that the antibacterial activity of EtOH extract was highest against all four strains of bacteria and was also comparable to the standard medicines used. The activity of $\mathrm{EtOH}: \mathrm{H}_{2} \mathrm{O}$ extract was found relatively less than EtOH extract but greater than $n$-hexane and acetone extracts, whereas the activity of $n$-hexane extract was the least. From the obtained results it can be concluded that slightly more polar compounds present in EtOH extract possess superior antibiotic character in nature in comparison to non-polar components of $n$-hexane extract and highly polar components of EtOH: $\mathrm{H}_{2} \mathrm{O}$ extract. The graphical representation of these results has been shown in Figure 1.

\subsection{Antifungal activities}

Antifungal activities of crude plant extracts were determined using

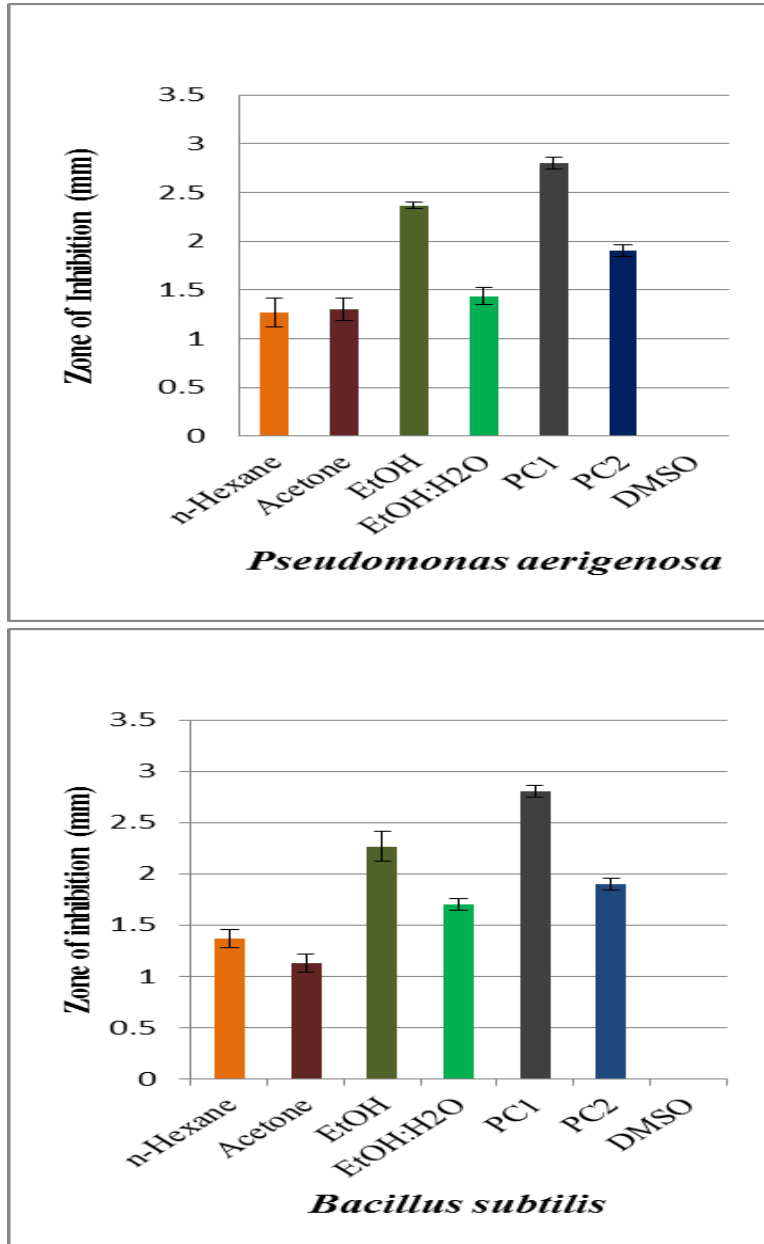

the agar-tube-dilution method. Two toxic fungal strains (F.moniliforme and H.sativum) were used to analyze the antifungal activities of these A. conyzoides extracts. A. conyzoides very strongly suppressed the growth of the fungal strains used, therefore this plant is anticipated for the isolation of the compounds with excellent antifungal characteristics. Results obtained after antifungal activities have been shown in Figure 2. In the present study, the obtained results illustrated that all the crude extracts have demonstrated strong in-vitro antifungal activities against two toxic fungal strains that were used in the experiments in various degrees. Results of antifungal activity indicated the highest activity of EtOH: $\mathrm{H}_{2} \mathrm{O}$ extract against both fungal strains. Whereas activity of acetone and ethanol extracts were also appropriate and comparable to standard drugs against $F$. moniliforme. These results indicated that polar compounds extracted by polar solvents were more antifungal. Therefore, the extract of highest polarity i.e., EtOH: $\mathrm{H}_{2} \mathrm{O}$ extract showed the highest activity and the extract of lowest polarity i.e., $n$-hexane extract, showed the lowest activity. Results of antifungal activities have been shown in Figure 2 .

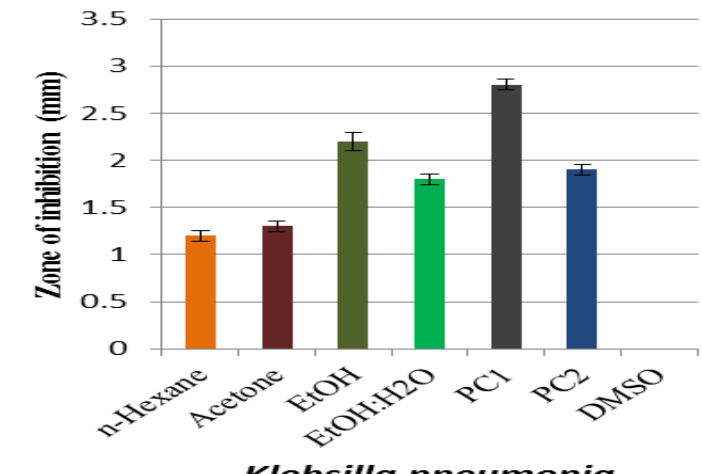

Klebsilla pneumonia

Figure 1 Graphical representation of antibacterial activities of four different extracts of $A$. conyzoides against different bacterial strains. 

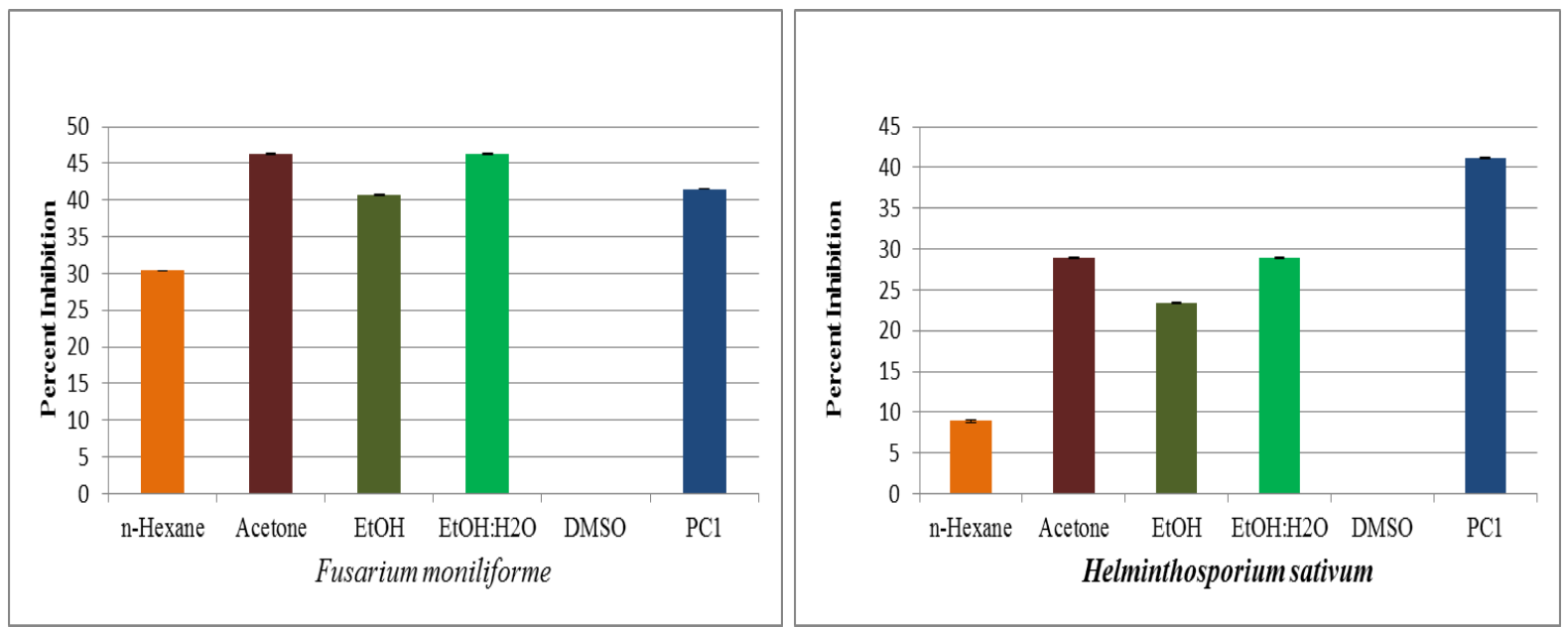

Figure 2 Graphical representation of the antifungal activity of four extracts of A. conyzoides against Helminthosporium sativum and Fusarium moniliforme.

Table 2 DPPH Radical Scavenging Activity of $\mathrm{Me}_{2} \mathrm{CO}$ extract of roots of A. conyzoides.

\begin{tabular}{|ccccccccccc|}
\hline S.N. & DPPH & AA & $100 \mu \mathrm{g}$ & $50 \mu \mathrm{g}$ & $25 \mu \mathrm{g}$ & $12.5 \mu \mathrm{g}$ & $6.25 \mu \mathrm{g}$ & $3.12 \mu \mathrm{g}$ \\
\hline 1 & 0.723 & 0.024 & 0.378 & 0.488 & 0.545 & 0.594 & 0.624 & 0.63 \\
\hline 2 & 0.736 & 0.024 & 0.381 & 0.485 & 0.561 & 0.609 & 0.631 & 0.648 \\
\hline 3 & 0.735 & 0.023 & 0.388 & 0.495 & 0.567 & 0.601 & 0.634 & 0.65 & 1.928 \\
\hline 4 & 2.194 & 0.071 & 1.147 & 1.468 & 1.673 & 1.804 & 0.889 & 0.630 & 0.643 \\
\hline Mean & 0.731 & 0.024 & 0.382 & 0.489 & 0.558 & 0.601 & 0.002 & 0.001 & 0.000 \\
\hline $\begin{array}{c}\text { Test sample + } \\
\text { Solvent }\end{array}$ & - & - & 0.028 & 0.013 & 0.006 & 0.043 & 0.629 & 0.643 \\
\hline Final absorbance & 0.731 & 0.024 & 0.354 & 0.476 & 0.552 & 0.599 & -18.058 & -13.95 & -12.04 \\
\hline Inhibition (\%) & - & -96.72 & -51.57 & -34.88 & -24.48 & &
\end{tabular}

\subsection{Antioxidant activities}

The DPPH free radical scavenging activities were presented as inhibition percentage and results are exhibited in Table 2. The obtained results varied from 12.04 to $96.72 \%$ for the acetone extract. The antioxidant activity was considerably observed in the $\mathrm{Me}_{2} \mathrm{CO}$ extract as compared to other extracts. The $\mathrm{IC}_{50}$ values of standard ascorbic acid and $\mathrm{Me}_{2} \mathrm{CO}$ extract were calculated with the help of $\mathrm{EZ}$ fit ${ }^{\mathrm{TM}}$ enzyme kinetic software (statistical software) (Table 2). From the $\mathrm{IC}_{50}$ value, it could be observed that $\mathrm{Me}_{2} \mathrm{CO}$ extract exhibits moderate antioxidant activity. Acetone extracts showed moderate hydroxyl free radical scavenging activity. This study leads to the conclusion that the polar constituents of roots of this plant exhibited higher antioxidant activity as compared with non-polar constituents.

\section{Conclusion}

The phytochemical screening exhibited the presence of various useful compounds in the root extract of A. conyzoides including terpenoids, alkaloids, coumarins, sterols, flavonoids, and glycosides. Moreover, the results indicated reasonable antibacterial (against both gram-positive and gram-negative bacteria), antifungal, and antioxidant potentialities, thus favoring the importance of the roots of this plant from a medicinal point of view. Keeping in view the biological activities of the phytochemicals identified in the roots of this plant, it can be stated that this plant could be a potential candidate for modern medicinal formulations.

\section{Conflict of interest}

The authors declared that they have no conflict of interest.

\section{References}

Al-Kaabi WJ, Albukhaty S, Al-Fartosy AJ, Al-Karagoly HK, AlMusawi S, Sulaiman GM, Soliman DA (2021) Development of Inula graveolens (L.) plant extract electrospun/polycaprolactone 
nanofibers: a novel material for biomedical application. Applied Sciences 11(2): 828 .

Bamidele O, Akinnuga AM, Anyakudo MMC, Ojo OA, Ojo GB, Olorunfemi O, Johnson OP (2010) Haemostatic effect of methanolic leaf extract of Ageratum conyzoides in albino rats. Journal of Medicinal Plants Research 4: 2075-2079.

Batish DR, Singh HP, Kaur S, Kohli RK (2006) Phototoxicity of Ageratum conyzoides residues towards growth and nodulation of Cicer arietinum. Agriculature, Ecosystems and Environment 113: 399-401.

Bilal M, Iqbal MS, Shah SB, Rasheed T, Iqbal H (2018) Diabetic complications and insight into antidiabetic potentialities of ethnomedicinal plants: a review. Recent patents on inflammation \& allergy drug discovery 12(1):7-23.

Bilal M, Munir H, Iqbal HM (2020) Potentialities of Medicinal Plant Extracts Against Biofilm-Forming Bacteria. In: Microbial Biofilms, CRC Press, Pp. 187-203.

Cannell R JP Ed (1998): Natural products isolation in: Methods in Biotechnology, Human Press, Totowa, New Jersey. Pp. 343-363.

Chah KF, Eze CA, Emuelosi CE, Esimone CO (2006) Antibacterial and wound healing properties of methanolic extracts of some Nigerian medicinal plants. Journal of Ethnopharmacology 104(1-2):164-167.

Ganesh S, Vennila JJ (2011) Phytochemical analysis of Acanthus ilicifolius and Avicennia officinalis by GC-MS. Research Journal of Phytochemistry 5: 60-65.

Harjanti DW, Ciptaningtyas R, Wahyono F (2019) Phytochemical properties and antibacterial activity of Ageratum conyzoides, Piper betle, Muntinga calabura and Curcuma domestica against mastitis bacteria isolates. In IOP Conference Series: Earth and Environmental Science 247(1): 012049.

Ishaq N, Bilal M, Iqbal H (2019) Medicinal potentialities of plant defensins: A review with applied perspectives. Medicines 6(1): 29.

Kamboj A, Saluja AK (2010) Microscopical and Preliminary Phytochemical Studies on Aerial Part, (Leaves and Stem) of Ageratum conyzoides Linn. Journal of Pharmacy Research 3: 432434.

Kamboj A, Saluja AK (2011) Isolation of stigmasterol and $\beta$ sitosterol from petroleum ether extract of aerial parts of Ageratum conyzoides (Asteraceae). International Journal of Pharmacy and Pharmaceutical Sciences 3(1): 94-96.
Khalid M, Bilal M, Hassani D, Iqbal HMN, Huang D (2017a) Antimicrobial, antioxidant, cytotoxicity and LC-MS analyses of Aerva javanica: an ethnomedicinally important plant. Journal of biological regulators and homeostatic agents 31(4): 963-969.

Khalid M, Bilal M, Hassani D, Zaman S, Huang D (2017b) Characterization of ethno-medicinal plant resources of karamar valley Swabi, Pakistan. Journal of Radiation Research and Applied Sciences 10(2): 152-163.

Khalid M, Bilal M, Huang DF (2019) Role of flavonoids in plant interactions with the environment and against human pathogensA review. Journal of Integrative Agriculture 18(1): 211-230.

Khalid M, Hassani D, Bilal M, Butt ZA, Hamayun M, Ahmad A, Hussain A (2017c) Identification of oral cavity biofilm forming bacteria and determination of their growth inhibition by Acacia arabica, Tamarix aphylla L. and Melia azedarach L. medicinal plants. Archives of Oral biology 81: 175-185.

Mehreen A, Waheed M, Liaqat I, Arshad N (2016) Phytochemical, antimicrobial, and toxicological evaluation of traditional herbs used to treat sore throat. BioMed Research International 2016: 8503426. doi: 10.1155/2016/8503426.

Muhammad N, Saeed M, Khan H (2012) Antipyretic, analgesic and anti-inflammatory activity of Viola betonicifolia whole plant. BMC complementary and alternative medicine 12(1): 1-8.

Mulugeta T, Legesse A, Yinebeb T (2021). Phytochemical Screening and Evaluation of Antibacterial Activities of Root Bark Extracts of Moringa stenopetala. Research Journal of Medicinal Plants15: 1-6.

Munir H, Bilal M, Mulla SI, Khan HA, Iqbal HM (2021) PlantMediated Green Synthesis of Nanoparticles. In: Advances in Green Synthesis, Springer, Cham, Pp. 75-89.

Okamoto Y, Suzuki A, Ueda K, Ito C, Itoigawa M, Furukawa H, Nishihara T, Kojima N (2006) Anti-estrogenic activity of prenylated isoflavones from Millettia pachycarpa: Implications for pharmacophores and unique mechanisms. Journal of Health Science 52: 186-191.

Okunade AL (2002) Review: Ageratum conyzoides L. (Asteraceae). Fitoterapia 73: 1-16.

Panda SK, Patra N, Sahoo G, Bastia AK, Dutta SK (2012) Antidiarrheal activities of medicinal plants of Similipal Biosphere Reserve, Odisha, India. International Journal of Medicinal and Aromatic Plants 2(1): 123-134.

Parveen S, Godara R, Katoch R, Yadav A, Verma PK, Katoch M, Singh NK (2014) In vitro evaluation of ethanolic extracts of 
Ageratum conyzoides and Artemisia absinthium against cattle tick, Rhipicephalus microplus. The Scientific World Journal 2014 :858973. doi: 10.1155/2014/858973.

Rawat P, Singh PK, Kumar V (2017) Evidence based traditional anti-diarrheal medicinal plants and their phytocompounds. Biomedicine \& pharmacotherapy 96: 1453-1464.

Rosangkima G, Prasad SB (2004) Antitumour activity of some plants from Meghalaya and Mizoram against murine ascites Dalton.s lymphoma. Indian Journal of Experimental Biology 10 981-8.

Sachin J, Neetesh J, Tiwari A, Baleka N, Jain DK (2009) Simple Evaluation of wound healing activity of polyherbal formulation of roots of Ageratum conyzoides Linn. Asian Journal of Research Chemistry 2: 135-138.

Shafiq N, Yasmin F, Noreen S, Shahzad A, Rashid M, Bilal M (2021) Phytochemical Profiling of Medicinal Plants Extracts and Their Antioxidant and Anticancer Potentialities Against Human Liver Cancer (Hep G2) Cell Lines. Revista de Chimie 72(2): 1.

Tiwari P, Kumar B, Kaur M, Kaur G, Kaur H (2011) Phytochemical screening and extraction. Internationale Pharmaceutica Sciencia 1: 98-106.
Trease GE, Evans WC (1989) Pharmacognosy, 13th ed. London (UK): ELBS Oxford University Press Pp. 245-263.

Uddin SB, Mahabub-Uz-ZamanM, Akter R, Ahmed NU (2009) Antidiarrheal activity of ethanolic bark extract of Mitragyna diversifolia. Bangladesh Journal of Pharmacology 4(2): 144146.

Wang Q, Kuang H, Su Y, Sun Y, Feng J, Guo R, Chan K (2013) Naturally derived anti-inflammatory compounds from Chinese medicinal plants. Journal of ethnopharmacology. 146(1): 9-39.

Washington JA, Sutter VL (1980) Dilution Susceptibilty test, Agar and Microbroth Dilution Procedure, Manual of Clinical Microbiology, 3rd Edition. American Society of Microbiology Pp. 453.

Wendel GH, Maria AOM, Guzmán JA, Giordano O, Pelzer LE (2008) Antidiarrheal activity of dehydroleucodine isolated from Artemisia douglasiana. Fitoterapia 79(1): 1-5.

Zafar M, Khan MA, Ahmad M, Sultana S (2006) Palynological and taxonomic studies of some weeds from flora of rawalpindi. Pakistan Journal of weed science society (1-2): 99-109. 